\title{
A Cluster-Randomized Trial of a Mobile Produce Market Program in 12 Communities in North Carolina: Program Development, Methods, and Baseline Characteristics
}

Lucia A. Leone, PhD; Gina L. Tripicchio, PhD, MSEd; Lindsey Haynes-Maslow, PhD, MHA; Jared McGuirt, PhD, MPH; Jaqueline S. Grady Smith; Janelle Armstrong-Brown, PhD; Sarah D. Kowitt, PhD, MPH; Ziya Gizlice, PhD; Alice S. Ammerman, DrPH

\section{ARTICLE INFORMATION}

Article history:

Submitted 26 July 2017

Accepted 15 April 2018

Available online 23 June 2018

\section{Keywords:}

Food environment

Mobile market

Lower-income

Cluster-randomized trial

Fruits and vegetables

https://doi.org/10.1016/j.jand.2018.04.010

\begin{abstract}
Background Mobile markets are an increasingly popular method for providing access to fresh fruits and vegetables $(\mathrm{F} / \mathrm{V})$ in underserved communities; however, evaluation of these programs is limited, as are descriptions of their development, study designs, and needs of the populations they serve.
\end{abstract}

Objective Our aim was to describe the development and theoretical basis for Veggie Van (VV), a mobile produce market intervention, the study design for the VV evaluation, and baseline characteristics of the study population.

Design The protocol and sample for a cluster-randomized controlled trial with 12 sites are described.

Participants/setting Community partner organizations in the Triangle region of North Carolina that primarily served lower-income families or were located in areas that had limited access to fresh produce were recruited. Eligible individuals at each site (older than 18 years of age, self-identified as the main shoppers for their household, and expressed interest in using a mobile market) were targeted for enrollment. A total of 201 participants at 12 sites participated in the VV program and evaluation, which was implemented from November 2013 to March 2016.

Main outcome measures Change in F/V intake (cups/day), derived from self-reported responses to the National Cancer Institute F/V screener, was the main outcome measure. Statistical analyses performed We performed a descriptive analysis of baseline sample characteristics.

Results Mean reported F/V intake was 3.4 cups/day. Participants reported generally having some access to fresh $\mathrm{F} / \mathrm{V}$, and $57.7 \%$ agreed they could afford enough $\mathrm{F} / \mathrm{V}$ to feed their family. The most frequently cited barriers were cost (55.7\%) and time to prepare F/V (20.4\%). Self-efficacy was lowest for buying more F/V than usual and trying new vegetables.

Conclusions By addressing cost and convenience and building skills for purchasing and preparing $\mathrm{F} / \mathrm{V}$, the $\mathrm{VV}$ has the potential to improve $\mathrm{F} / \mathrm{V}$ consumption in underserved communities.

J Acad Nutr Diet. 2019;119(1):57-68.

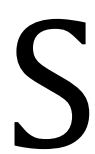
TUDIES IN THE UNITED STATES HAVE CONSISTENTLY found that lower-income individuals consume fewer fruits and vegetables (F/V) than higher-income individuals. ${ }^{1-3}$ A healthy diet, including $\mathrm{F} / \mathrm{V}$, helps support healthy weight and reduces the risk of diet-related chronic disease. ${ }^{4,5}$ In turn, overweight and obesity rates are usually highest in neighborhoods with limited incomes and high poverty rates. ${ }^{6,7}$ Lower-income neighborhoods tend to have fewer healthy food outlets (grocery stores, supermarkets, farmers' markets) and a higher proportion of convenience stores or fast-food restaurants that sell low-nutritional-value foods. ${ }^{8,9}$ Thus, poorer diets and subsequent higher rates of diet-related chronic disease among lower-income individuals may be partially attributed to reduced access to fresh $\mathrm{F} / \mathrm{V}$ and other healthy foods.

$\mathrm{F} / \mathrm{V}$ access is affected by several factors, including availability, accessibility, affordability, acceptability, and accommodation. ${ }^{10}$ While $\mathrm{F} / \mathrm{V}$ availability is limited in many areas, even in areas where healthy food appears abundant (ie, high availability), many lower-income individuals do not perceive they can access $\mathrm{F} / \mathrm{V}$ because of cost (affordability); transportation (accessibility); low quality or variety (acceptability); limited store/market hours (accommodation); or other personal-level factors, such as lack of nutrition 
education or food preparation skills. ${ }^{11-14}$ Previous research among low-income North Carolinians found that the most commonly cited barriers to eating $\mathrm{F} / \mathrm{V}$ were cost and not having time to prepare $\mathrm{F} / \mathrm{V} .^{15}$

While access to healthy food is theoretically important for improving dietary intake and overall health, research on the role of the food environment has been largely limited to cross-sectional observational studies, ${ }^{16}$ and there is limited literature on the effects of interventions to increase availability of food retail outlets. ${ }^{17}$ A 2009 summary of food environment research concluded that the presence of grocery stores or supermarkets in communities was likely associated with increased F/V intake, however, these conclusions were based primarily on cross-sectional studies. ${ }^{18} \mathrm{~A}$ more recent analysis of longitudinal data collected from young adults reported that geographic access to more supermarkets was not related to F/V consumption. ${ }^{19}$ Another study used a natural experiment to compare changes over time in an underserved neighborhood in Pittsburgh, PA, where a new grocery store was built, to that of a similar neighborhood that did not receive a new store. Residents in the neighborhood with the new grocery store showed improvements in diet quality, but there were no changes in body mass index (calculated as $\mathrm{kg} / \mathrm{m}^{2}$ ), $\mathrm{F} / \mathrm{V}$ intake, or whole-grain consumption. ${ }^{20}$ The grocery store did improve residents' perceived access to healthy food and neighborhood satisfaction. Surprisingly, changes in diet, perceived access to healthy food, and neighborhood satisfaction occurred regardless of whether residents were frequent shoppers of the grocery store.

The few intervention studies that focused on improving F/V access and intake have been implemented using pre-post designs. The Veggie Mobile in Albany, NY, sold fresh produce to individuals living in a senior housing community; people who used the program increased their average $\mathrm{F} / \mathrm{V}$ intake by 0.37 servings/day (about 0.19 cups). ${ }^{21}$ Another study implemented a farmer's market program at a South Carolina federally qualified health center and found an increase in F/V of 1.6 servings/day (about 0.8 cups). ${ }^{22}$ Lastly, a study of a farm stand in a lower-income community found that $\mathrm{F} / \mathrm{V}$ intake in the surrounding community increased 0.42 servings/day (about 0.21 cups); while this overall difference was not statistically significant $(P=0.21)$, they did show statistically significant increases in consumption of fruit, juice, tomatoes, salad, and other vegetables, but again lacked use of a control group. ${ }^{23}$ All of these studies were limited to a single population and location.

A pilot evaluation of the Veggie Van (VV) program in North Carolina improved upon previous work by looking at the impact of a mobile produce market in multiple communities over nearly 3 years. VV delivered weekly boxes of fresh, local produce and nutrition education in communities with limited access to fresh F/V. Participants at pilot sites who used VV weekly or every other week were more likely to report increases in $\mathrm{F} / \mathrm{V}$ consumption at follow-up compared to people who rarely or never used $\mathrm{VV}^{24}$ Frequent VV shoppers $(n=32)$ increased their $F / V$ consumption by 0.41 servings/day compared with a decrease of -1.19 servings/day for those who rarely/never used VV $(n=27)$. The total difference of 1.6 servings/day $(P=0.01)$ was approximately equivalent to a 0.8 -cup/day difference. Participants also reported that the VV helped them make other positive dietary changes, including eating healthier snacks and consuming

\section{RESEARCH SNAPSHOT}

Research Question: What are the characteristics of people who are interested in shopping at a theory-based mobile produce market (Veggie Van), which was designed to increase fruit and vegetable (F/V) access among lowerincome individuals?

Key Findings: While objective and subjective measures indicated that participants had some access to fresh F/V in their neighborhood, F/V intake was still low in this population. The Veggie Van program may help participants overcome common barriers to eating F/V (eg, time and cost) and improve their self-efficacy (ie, confidence in their own ability) for purchasing, eating, and preparing fresh produce.

less sodium and fewer "bad" fats. As with previous studies, findings from the VV pilot suggest that changes to the community food environment could have a positive impact on residents' diets. Given the promise of VV pilot program and other mobile market programs, there was a need for a more rigorous study to better understand how changes to the food environment would impact diet. ${ }^{17}$

This article discusses the design of VV and its evaluation using a cluster randomized controlled trial (RCT) design. The goal of the VV evaluation was to examine the effects of VV on consumption of $\mathrm{F} / \mathrm{V}$ in 12 lower-income and underserved communities. Secondary outcomes included perceived access to fresh F/V and self-efficacy to purchase, prepare, and eat fresh $\mathrm{F} / \mathrm{V}$. While mobile market programs are becoming increasingly popular, only one other study has used an RCT design, and the findings are not yet available. ${ }^{25}$ This article adds to the literature by detailing a rigorous evaluation of a mobile market program that involves collaboration between researchers, community groups, and businesses. Given the limited research in this area, it is important to communicate the various approaches to program development, implementation, and evaluation to guide future trials. The goal of this article is to describe the development process and theoretical approach used to design the VV program; describe the methods for the evaluation of the VV program; and describe the baseline characteristics of the study sample. Main outcomes of this evaluation are published separately. ${ }^{26}$

\section{MATERIALS AND METHODS}

The VV program was developed by the North Carolina-based nonprofit organization, Community Nutrition Partnership, in collaboration with members of the research team. To inform program development, 13 focus groups were conducted across five counties in North Carolina to better understand strategies for improving access to healthy food in lowerincome communities. ${ }^{27}$ On a post-focus group survey, $88 \%$ of participants indicated that they would be likely to use a mobile market program. ${ }^{28}$ The demonstrated interest in a mobile market program led Community Nutrition Partnership to develop the VV program. First, the VV program was evaluated at one initial pilot site (a lower-income housing community). ${ }^{24}$ Given the success and promise of the pilot site, an expansion of the VV program was planned. In addition, funding was awarded to evaluate the VV program 
cluster RCT. Findings from baseline data collected between November 2013 and October 2015 are also reported.

\section{Theoretical Model}

In addition to formative work, the Socio-Ecological Model (SEM) and Social Cognitive Theory (SCT) informed the design of this intervention. The SEM acts as a guiding framework for addressing the complexities associated with dietary intake in high-need populations. The SEM posits that multiple levels (eg, individual, interpersonal, and community-level factors) intersect to influence behavior. ${ }^{29}$ Programs that target change in F/V availability in high-need communities are lacking, and multi-level interventions are generally more effective than those targeting a single level of influence. ${ }^{30}$

The SCT provides constructs that link individual psychosocial and environmental changes to related dietary behaviors. The SCT offers the concept of reciprocal determinism, which emphasizes the interdependent influences among individuals, their behaviors, and the environments in which they live. ${ }^{31}$ This theory suggests that changing the food environment alone is not enough, but how individuals perceive and interact with that environment is also important. Thus, the VV program was designed to address the interplay among the physical food environment, individual perceptions of their food environment, and self-efficacy for $\mathrm{F} / \mathrm{V}$ consumption using two primary intervention components: food access component and educational component. Together these components target multiple levels of change: the food environment and individual level factors that affect F/V consumption (Figure).

Self-efficacy, or the confidence in one's ability to perform a desired behavior, is a key psychosocial determinant emphasized by SCT. ${ }^{31}$ The VV educational component was designed to increase self-efficacy for purchasing, preparing, and eating $\mathrm{F} / \mathrm{V}$ by decreasing individual-level barriers to F/V consumption. Specifically, the educational component focused on increasing behavioral capability, observational learning, and outcome expectations/expectencies related to F/V consumption. The food access component was designed to change barriers presented by the food environment and subsequently change participant's perceptions of it by addressing multiple aspects of $\mathrm{F} / \mathrm{V}$ access (availability, accessibility, affordability, acceptability, and accommodation). ${ }^{16}$ As the food environment shifts toward one of increased access to $\mathrm{F} / \mathrm{V}$, individuals will have more opportunity to purchase highquality, affordable fresh produce. In order for them to take advantage of those opportunities, they need to have selfefficacy for buying, purchasing, and preparing fresh produce. As self-efficacy increases their ability to make the most of the opportunities in the food environment, their perceived access to fresh F/V should also increase. Based on the SCT, greater perceived access and higher self-efficacy will work synergistically (ie, the various parts work together to produce an enhanced result) to increase $\mathrm{F} / \mathrm{V}$ consumption. As the educational component of the VV addressed replacing sugary foods with $\mathrm{F} / \mathrm{Vs}$, an exploratory hypothesis was that increases in calories as the result of increased $\mathrm{F} / \mathrm{V}$ consumption would be compensated for through decreases in sugar intake.

\section{VV Food Access Component}

The VV program included a weekly mobile market program where staff and volunteers delivered local, seasonal, subsidized produce to locations at community partner sites. The mobile market was set up at each location for approximately 2 hours each week; operated year-round; and accepted cash, checks, Supplemental Nutrition Assistance Program electronic benefits, and credit/debit cards. The VV carried a variety of high-quality seasonal North Carolina produce items, which were available for individual sale or in "shares" (ie, a box of F/V meant for a certain number of people). Shares were available in two sizes: large (F/V for 4 to 5 people/week) or small ( $\mathrm{F} / \mathrm{V}$ for 2 to 3 people/week). Shares were priced on a sliding scale starting at $\$ 10$ for a small and participants chose the price they could afford without income verification. In order to help customers decide what to pay, VV offered three suggested price levels that included the cost of the produce (\$10 small/\$15 large); the cost of the produce and running the VV (\$17 small/ \$22 large); and the cost of one's own share

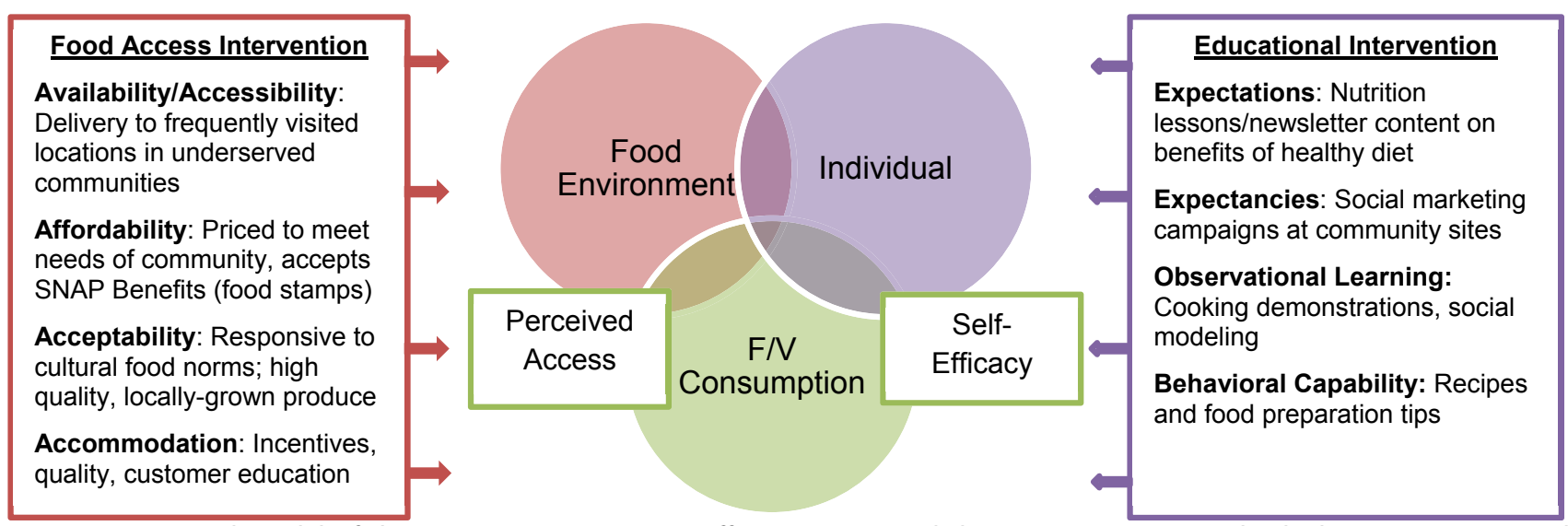

Figure. Conceptual model of the Veggie Van program's effect on reciprocal determinism among individuals, environment, and behavior. Reciprocal determinism is a construct within Social Cognitive Theory that suggests that individual and environmental factors interact and jointly influence behavior. In this case, we propose that changes in fruit and vegetable (F/V) consumption caused by the Veggie Van program will be mediated by increased self-efficacy to purchase prepare and eat F/V and increased perceived access to fresh fruits and vegetables. 
plus helping someone else in their community ( $\$ 18+$ small/ $\$ 23+$ large). The lowest price was similar to that of conventional produce (ie, not local or organic) available at discount supermarkets frequented by the target population and the middle price point was on par with local communitysupported agriculture programs. The lowest prices were set based on data collected in customer interest forms about household size and weekly F/V expenditures.

Most customers in the target communities included in this research chose to pay the lowest price, but other communities served by a Community Nutrition Partnership (eg, university faculty and staff, home delivery customers) that were not in this study, helped to support the program by paying more. In order to limit waste and help with inventory planning, customers were encouraged to purchase shares (rather than individual items) through marketing and pricing. For example, customers paying the lowest price could receive additional discounts by purchasing several weeks' worth of shares at once ( $\$ 1-2$ off per share). Individual items were generally priced higher than the lowest (subsidized) share price. In January 2015, VV implemented an online ordering and payment system, which customers could use to pre-order and/or pre-pay for shares. While preordering shares and advanced payment were encouraged, VV made every effort to accommodate new customers and walk-ups.

All research participants received a one-time voucher for free produce (an approximately $\$ 10$ value). Vouchers were sent to intervention participants at the completion of the baseline survey and control participants received their vouchers after follow-up with the start of the delayed intervention. Because baseline data collection was conducted before program implementation, there was no guarantee that participants would actually utilize the VV program. The voucher had a 3-month expiration to encourage early VV usage and ensure that it would not affect follow-up F/V intake.

\section{VV Educational Component}

The VV team developed a nutrition education curriculum that could be delivered in short interactions when customers were waiting to pick up their shares. Each month had a theme and weekly lessons were built on that theme. Examples of monthly themes included eating locally and in season, reading food labels, healthy substitutions, using MyPlate, and reducing sugar intake. All customers and research participants received newsletters that reinforced the lesson of the week and featured seasonal produce. Nutrition education, recipes, and cooking demonstrations were offered at sites as regularly as possible (based on staff and volunteer availability) and incorporated seasonal produce. Newsletters also included information about the current VV sites, hours and locations of mobile markets, and any program changes or special events. In order to facilitate intervention reach, the VV newsletter was e-mailed or mailed (based on participant preference) to all participants in the research study, regardless of whether or not they attended VV.

\section{VV Evaluation}

The VV program was evaluated using a cluster RCT. Twelve new community sites were recruited and randomized (two at a time) to receive the $\mathrm{VV}$ program or a delayed intervention control. Follow-up data collection was planned for 6 months post-baseline (while VV was still active at intervention sites). After 6-month follow-up, control sites were offered the VV program. Data collection at 12 months allowed the research team to look at changes in the delayed-intervention group and longer-term outcomes for intervention sites. All methods for evaluation were approved by the Institutional Review Board at the University of North Carolina at Chapel Hill; consent procedures are described.

\section{Site and Participant Recruitment}

Community organizations predominately serving lowincome individuals and/or located in areas with limited access to healthy food (eg, community/recreation centers, lower-income housing communities, federally qualified health clinics) were prioritized for study participation. Details about the site recruitment process can be found elsewhere. ${ }^{32}$ Briefly, a site liaison was identified at each site to serve as the primary contact for the program and assess community member interest in VV. Potential VV customers were asked to complete an interest form (online or paper) indicating their likelihood of using VV, and forms were used to enroll individual study participants at each site. In order to be eligible, people had to be at least 18 years of age, speak and understand English, act as the primary food purchaser for their household, and indicate an interest in using the VV program. Those that were eligible were asked to schedule a time to complete a 30-minute telephone-administered baseline survey. Before being called to complete the survey, potential participants received a consent document by e-mail or mail and a sample portion size sheet to use when answering dietary intake questions. At the beginning of the survey phone call, interviewers reviewed the consent document and informed participants that their completion of the survey would indicate their consent to participate in the study.

\section{Randomization}

Sites were recruited into the study on a rolling basis. Sites with similar timelines (ie, they were on track to finish baseline data collection around the same time) were randomized at the same time (one to control and one to intervention) to reduce the effect of seasonality. For the first four sites, randomization occurred after all baseline data had been collected. For the remaining sites, in order to balance program implementation and research time lines, randomization occurred after 15 participants were recruited at each of the sites that were randomized together. Intervention sites were informed of their randomization status immediately so that they could start planning for the VV kick-off. Baseline data collection continued at both sites until recruitment reached 25 participants (site goal) or the VV program started at the intervention site. Control sites were informed of their intervention status after baseline data collection was completed.

\section{Data Collection}

Data for this study were collected using three different methods: interview-administered survey; Geographic Information System (GIS) mapping; and VV sales data. Most individual data were collected via an interviewer-administered survey conducted over the phone at baseline, 6 months, and 
12 months. Interviewers were trained by the project manager to limit interviewer bias. Answers were entered directly into a web-based form developed using Qualtrics software ${ }^{33}$ to help facilitate skip patterns and minimize errors and missing data. GIS mapping was used to measure individual-level grocery store access (baseline) and sales data was used to measure VV usage (6 and 12 months). Sales data for study participants was extracted from VV sales records and shared with the research team.

\section{Survey Measures}

Measures for VV were initially tested using cognitive interviews at select pilot sites. Measures tested included: Perceived Nutrition Environment Measures Survey (NEMS-P), the National Cancer Institute's F/V screener (a food frequency questionnaire), selected barrier and self-efficacy questions, and some additional food access and process measures that were created specifically for this study. Two cognitive interview strategies were used: think-aloud interviewing and verbal probing. In "think-aloud" interviewing, researchers asked participants a question and then had them describe the processes they used in coming to an answer to the question. ${ }^{34}$ For verbal probing, researchers asked a survey question and then probed into the participant's answer with follow-up questions. ${ }^{34}$ A convenience sample of VV customers $(n=7)$ were recruited and each participant was interviewed by phone for approximately 45 to 60 minutes. Responses were analyzed for emerging themes and dominant trends across interviews. While participants understood many of the questions, some questions were challenging for participants to answer because of their wording, response options, ordering, and relevance. The research team met to review the findings and agreed upon which questions should be modified to improve face validity (ie, does the question measure what it is supposed to) and comprehension in the target population. Questions were modified as described in the Measures section.

F/V Intake. The main outcome-change in F/V consumption-was measured using a modified version of the National Cancer Institute F/V screener. ${ }^{35}$ This food frequency questionnaire collects frequency ("Over the last month, how many times did you eat [fruit/vegetable category]?") and portion size ("Each time you ate [fruit/vegetable category] how much did you usually eat?") for several categories of $\mathrm{F} / \mathrm{V}$ and uses a validated formula to calculate average F/V cups/ day over the past month. ${ }^{36}$ Results from the cognitive interview process prompted changes in the response options to allow participants to give an open answer (eg, three times per week) rather than selecting from a set range as in the original measures (eg, two to four times per week). During the pilot study, some participants wanted to report consumption of dried fruit, so an additional question was added to reflect this category. The final F/V outcome variable was comprised of foods from 10 categories: 100\% fruit juice, fruit (canned, fresh, or frozen), dried fruits or vegetables, lettuce salad, fried potatoes, other potatoes, beans, tomato sauce, vegetable soup, and other vegetables. During the pilot, it was found that frequency of $\mathrm{F} / \mathrm{V}$ consumption was similar across all participants at follow-up, but portion-size reports had decreased, leading to an overall decrease in $\mathrm{F} / \mathrm{V}$ consumption. This could have been due to participants gaining a better understanding of portion sizes at follow-up as a result of the VV educational component. To address this for the current study, portionsize example sheets were included in participant packets and they were asked to have it present during data collection.

Sugar Intake. Seven items were selected from the National Health and Nutrition Examination Survey Dietary Screener to capture self-reported consumption of added sugars in the past month, including sugar-sweetened beverages, chocolate or candy, pastries, desserts, or ice cream. ${ }^{37}$

Perceived Access to Fruits and Vegetables. A threequestion perceived access scale was used to measure participants' perceptions of access to fresh $\mathrm{F} / \mathrm{V}$ in their neighborhood, the area surrounding the VV community site at which they were recruited, and in general. The following items were selected from the NEMS- $\mathrm{P}^{38}$ : "It is easy to buy fresh fruits and vegetables [in my neighborhood/around community sites/ in general];" "There is a large selection of fresh fruits and vegetables [in my neighborhood/around community site/in general];" "The fresh fruits and vegetables [in my neighborhood/around community site/in general] are high quality." The prompt, which was slightly modified from previous scales based on cognitive interviewing, asked participants to "think about their neighborhood as the area within a 20-minute walk or about a mile from their home/ community site." An additional question was added to the general access scale: "I can afford to buy enough fresh fruits and vegetables for my family." For all perceived access questions, participants chose responses from a 5-point Likert scale ("strongly agree" $=5$ to "strongly disagree" $=1$ ). Each three-item scale was summed to create a perceived access score by location. Possible perceived access scores range from 3 points (strongly disagree to all items) to 15 points (strongly agree to all items), with a midpoint of 8 points. The fourth item on affordability was developed by the research team and refined using the cognitive interviewing process. Because it was not part of the original perceived access scale, responses were analyzed separately.

Barriers. A total of 12 questions were used to assess selfreported barriers to eating $\mathrm{F} / \mathrm{V}$. Questions were measured using a 4-point Likert response scale about each of the following empirically derived barriers: time, preparation skills, transportation, cost, liking, family preference, storage space, restaurant availability, and work availability. For analysis, strongly agree/agree and strongly disagree/disagree response options were combined to create a dichotomous variable. Items shown in Table 1 were adapted from a scale previously tested in lower-income adults, ${ }^{15}$ and reflect common benefits/barriers found in the literature. ${ }^{14,15,39,40}$

Self-Efficacy. Self-efficacy to purchase, prepare, and eat fresh $F / V$ was measured using a 10-point Likert scale (1=very easy, $10=$ very hard). A selection of 10 items were adapted from a study of shoppers where self-efficacy was shown to be correlated with nutrition behaviors. ${ }^{41}$ Participants were prompted to consider: "There are a number of different ways that people find time to buy, fix, and eat more fruits and vegetables. We would like to know how easy or hard you would find each of the following things to do." Participants 
Table 1. Barriers to fruit and vegetable consumption ${ }^{a}$ self-reported on the baseline survey by 201 adults participating in a randomized mobile market intervention

\begin{tabular}{llr} 
Barriers & Questions & \% Stron \\
\hline General & It is easy for me to eat fruits and vegetables. & 87.6 \\
Time & I do not have time to prepare fruits and vegetables. & 20.4 \\
Preparation skills & I do not know how to prepare fruits and vegetables. & 7.0 \\
Transportation & I do not have transportation to get to a place where & 10.0 \\
& I can get fruits and vegetables. & 55.7 \\
Cost & It costs too much money to buy fruits and vegetables. & 3.0 \\
Liking, fruit & I do not like fruits. & 1.5 \\
Liking, vegetables & I do not like vegetables. & 3.0 \\
Family preference, fruit & My family does not like fruits. & 6.5 \\
Family preference, & My family does not like vegetables. \\
vegetables & I do not have enough space to store fruits and \\
Storage space & vegetables in my home. & 6.0 \\
Restaurant availability & The restaurants I go to do not offer fruits and vegetables. \\
Work availability & Fruits and vegetables are not available at my work \\
& (in the cafeteria or other vending outlets). & 7.0 \\
aQQuestions adapted from a previously tested survey examining benefits, barriers, and facilitators to eating fruits and vegetables. ${ }^{14}$ & 37.3
\end{tabular}

were also asked about the importance of eating more $F / V$ using a 10 -point Likert scale $(1=$ not at all important; $10=$ very important): "Considering all of the things that require your time, attention, and money, how important is it for you to find ways to buy and fix more fruits and vegetables for yourself and your family?" All self-efficacy questions are presented in Table 2.

Shopping Behavior. Selected shopping behavior questions were taken from the NEMS-P. ${ }^{38}$ Participants were asked 20 questions to capture information about food shopping frequency, methods of transportation to food stores, and perceptions of produce prices, quality, and variety at the store where they most frequently shopped for food.

Demographics. Demographics collected at baseline included age, sex, race/ethnicity, household income, marital status, education, and receipt of government assistance. To assess government assistance, participants were asked to indicate whether anyone in their household participated in the following programs within the past 12 months: Supplemental Nutrition Assistance Program or "food stamps," Special Supplemental Nutrition Program for Women, Infants, and Children, free- or reduced-price school breakfast or lunch, Head Start, food pantry, Medicaid, or Temporary Assistance for Needy Families or welfare. Self-reported height and weight (from the baseline survey) was used to compute body mass index.

\section{GIS Measures}

Participant addresses and food stores were batch geocoded using the Google Maps geocoding application programming
Table 2. Self-efficacy ${ }^{a}$ for buying, eating, and preparing fruits and vegetables self-reported on the baseline survey by 201 adults participating in a randomized mobile market intervention

\section{How easy or hard would it before you to...} $\operatorname{Mean}^{\mathrm{b}} \pm \mathrm{SD}^{\mathrm{c}}$

Buy more fruits and vegetables than you $3.9 \pm 2.9$ normally do the next time you shop?

Use all of the fruits and vegetables that $3.9 \pm 2.7$ you buy before they go bad?

Work more fruits and vegetables than you normally do into meals for yourself and your family?

Work more fruits and vegetables than $3.8 \pm 2.8$ you normally do into snacks for yourself and your family?

Cook vegetables in a way that is appealing to your family?

Make-up a vegetable dish with what you have on hand?

Try vegetables that you have not $5.0 \pm 3.2$ eaten before?

Prepare and cook new recipes

aself-efficacy questions adapted from a Social-Cognitive Model of Nutrition Behavior. ${ }^{4}$

brom $1=$ very easy to $10=$ very hard.

${ }^{\mathrm{C}} \mathrm{SD}=$ standard deviation; accounting for clustering by site. 
interface through the BatchGeo ${ }^{42}$ website. ReferenceUSA ${ }^{43}$ was used to identify food stores. ReferenceUSA verifies the listings in this online business database on a yearly basis via phone ${ }^{44-46}$ and the research team verified listing at the time of mapping for any listing that did not geocode at the highest level of accuracy (according to Batch $\mathrm{GeO}^{42}$ ) through Google searches and satellite imagery. A custom search identified supermarkets, grocery stores, supercenters, and convenience stores (with or without gas stations) for each of the study's four counties (Alamance, Durham, Orange, and Wake). Using the North American Industry Classification System, ${ }^{47}$ the following codes were used to identify supermarkets (445110), grocery stores (445110), convenience stores (445120), convenience stores with gas stations (447110) and supercenters (452910). To characterize the food environment context around each participant, ArcGIS10.2 $2^{48}$ was used to calculate the number of each type of store within a 1- and 3-mile radius of participants' homes.

\section{Power Analysis}

Our original power analysis was based on $\mathrm{F} / \mathrm{V}$ servings/day as calculated by the National Cancer Institute F/V screener. ${ }^{26}$ Sample size estimates considered correlated change in $\mathrm{F} / \mathrm{V}$ intake among participants within a community site (intraclass correlation coefficient), number of participants within each site, and number of sites (clusters). ${ }^{49,50}$ The VV program was expected to increase the $\mathrm{F} / \mathrm{V}$ consumption by least 1.25 servings per day or approximately 0.75 cups/day (effect size of approximately 0.35 ) based on the VV pilot. ${ }^{24} \mathrm{~A}$ sample size of six communities per group with 20 participants in each community yielded 0.80 power to detect 0.75 -cup difference in mean changes between two groups using two-sided tests of significance at $P=0.05$, assuming an intraclass correlation coefficient of 0.001 and standard deviation (SD) of 3.6 based on other cluster randomized trials. ${ }^{51}$ Attrition was assumed to be no more than $20 \%$, based on the pilot study. ${ }^{24}$ Thus, a final goal was to recruit at least 25 participants in each community, for a total of 300 participants.

\section{Data Analysis}

Baseline sample characteristics, including sociodemographics, dietary intake, perceived $\mathrm{F} / \mathrm{V}$ access, barriers to $\mathrm{F} / \mathrm{V}$ intake, and food environments based on GIS mapping, were analyzed using descriptive statistics and are presented as means and SDs (and medians for main scales of interest) for continuous variables and as percentages for categorical variables. Sample characteristics are presented for the entire sample and by intervention and control group. Comparisons between intervention and control account for clustering within sites. Baseline values for selected psychosocial variables for the entire sample are also presented. All descriptive analyses were conducted using Stata software, version $9 .^{52}$

\section{RESULTS}

Demographic characteristics presented for all study participants $(\mathrm{n}=201)$ and by intervention and control conditions, are shown in Table 3. Most participants were female (93.0\%), African American (61.1\%), had a household income between $\$ 10,000$ and $\$ 30,000$ (32.0\%), and reported never being married (47\%). The mean age was $45.2(\mathrm{SD}=13.6)$ years and mean body mass index was $31.3(\mathrm{SD}=7.7)$. The majority
(62.6\%) reported receiving at least one form of government assistance. A total of 113 participants were recruited in sites randomized to the intervention group and 88 in sites randomized to the control group.

\section{Food Access and Shopping Behaviors}

The mean overall perceived access score among participants was 11.1 ( $\mathrm{SD}=3.1$, median=12), and $57.7 \%$ of respondents agreed or strongly agreed that they could afford enough fresh F/V for their family (data not shown). Perceived access to fresh $F / V$ near participants' homes was slightly lower ( mean $=10.3, \mathrm{SD}=3.4$, median $=11$ ). A score of 10.3 indicated that, on average, participants somewhat agreed that a good variety of high-quality $\mathrm{F} / \mathrm{V}$ were available within 1 mile of their home. Among all perceived access subscales, perceived access in relation to the 1-mile radius around the community site was rated lowest by participants: mean $=8.5(\mathrm{SD}=3.4$, median $=8)$. On average, GIS mapping identified $2.0(\mathrm{SD}=2.1)$ grocery stores, supermarkets, or supercenters and 4.3 $(\mathrm{SD}=4.3)$ convenience stores within 1-mile of participants' homes (Table 3).

When asked where participants did the majority of their shopping, participants answered as follows: supermarket (71.1\%), supercenter $(24.9 \%)$, small grocery store $(2.5 \%)$, other $(1.0 \%)$, and farmers' market $(0.5 \%)$. The majority of people shopped for groceries at least once per week $(62.2 \%)$ and traveled to the store in their own car (78.6\%); only $10 \%$ of people reported using public transportation or active travel (ie, walking, biking) to get to the store and the rest reported traveling with a friend or borrowing a car.

\section{Dietary Behaviors and Attitudes}

On average, $\mathrm{F} / \mathrm{V}$ consumption was $3.4(\mathrm{SD}=2.5$, median $=2.8$, range $=0.03$ to 23.1) cups/day and participants reported 2.1 ( $\mathrm{SD}=2.2$, median $=1.7$, range $=0$ to 20.1 cups/day) servings/ day of added sugars (Table 3). Self-reported barriers to F/V consumption are detailed in Table 1. Participants reported few barriers to eating $\mathrm{F} / \mathrm{V} ; 87.6 \%$ agreed or strongly agreed that it was easy for them to eat $\mathrm{F} / \mathrm{V}$. The most frequently reported barriers were cost (55.7\%) and time (20.4\%). Also, among people who worked, $37.3 \%$ said that they did not have F/V available at their workplace. Self-efficacy for buying, preparing, and eating $\mathrm{F} / \mathrm{V}$ is detailed in Table 2. Of all scale items, participants reported the lowest self-efficacy for trying new vegetables; on a scale of 1 to 10 points, with 10 points being very hard, participants rated this $4.9(\mathrm{SD}=3.2)$ points. All other scores were rated a 4.0 or lower, indicating that participants were somewhat confident in their ability to carry out these behaviors. Participants reported high ratings in response to the questions asking about the importance of eating more $\mathrm{F} / \mathrm{V}$ : $9.0(\mathrm{SD}=1.5)$ points on a scale of 1 to 10 points (data not shown).

\section{DISCUSSION}

This study is an example of applying a community-based approach to developing and evaluating a food-access intervention. Studies have shown that community-based interventions can be an effective way to produce behavioral and environmental change in a community setting. ${ }^{53}$ This is one of the first cluster RCTs to evaluate a mobile produce market and, to date, the only one implemented by a nonprofit 
Table 3. Baseline characteristics of 201 adults participating in a randomized mobile market intervention in North Carolina

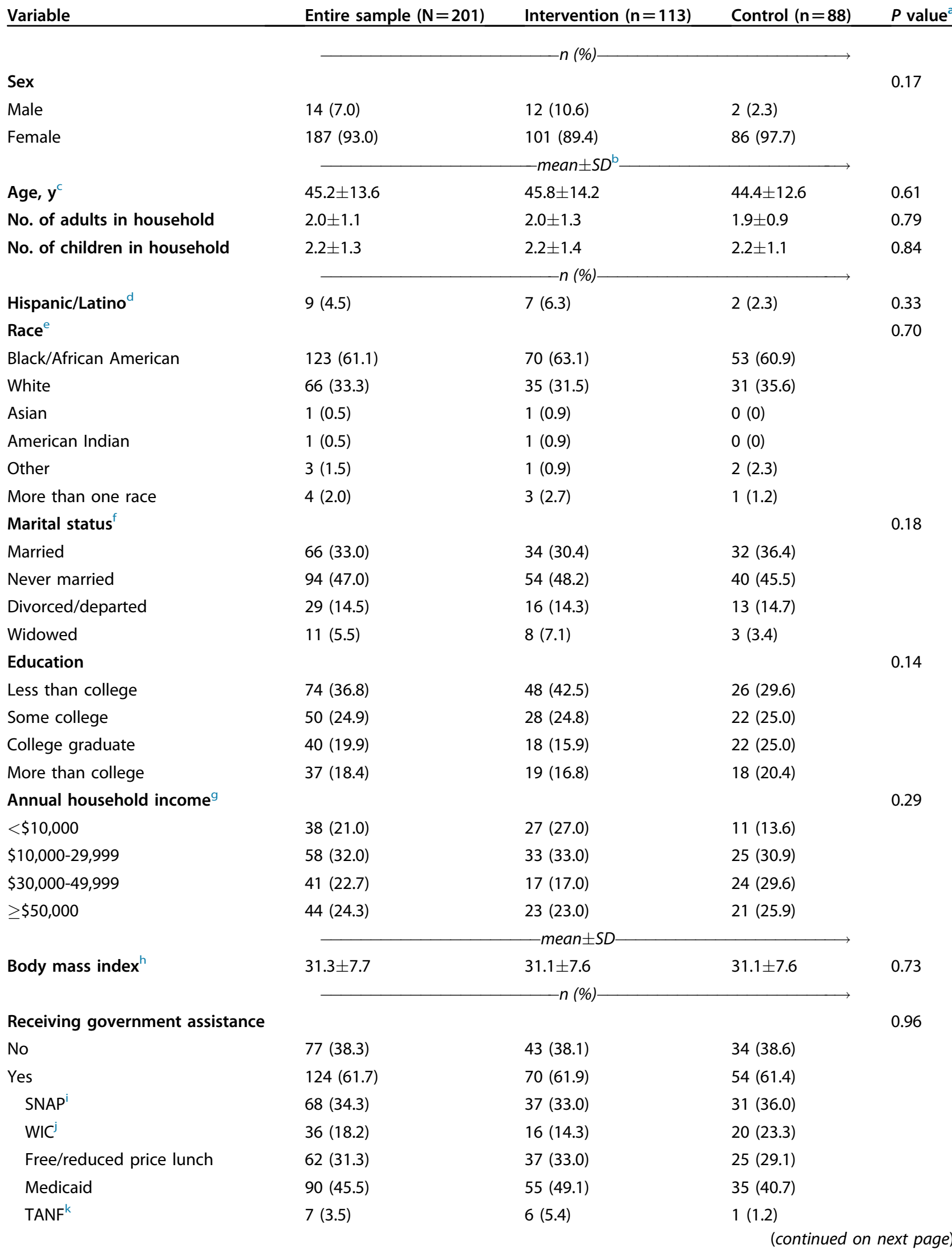


Table 3. Baseline characteristics of 201 adults participating in a randomized mobile market intervention in North Carolina (continued)

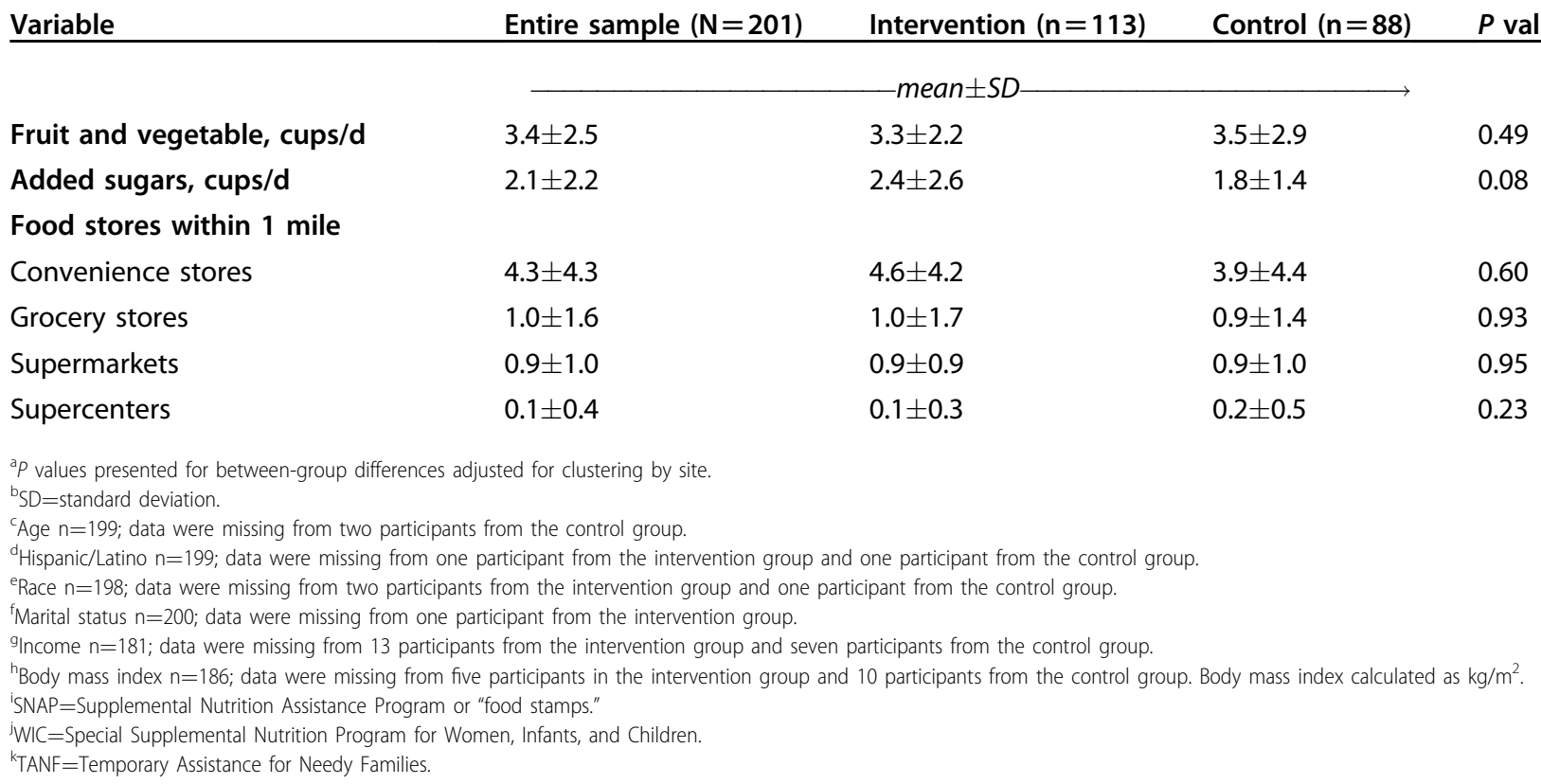

organization and evaluated in cooperation with researchers. This collaborative approach was important, as mobile market interventions implemented by researchers may be less likely to continue past the initial evaluation stage, despite promising results. In addition to measuring the impact of the program itself, this research could potentially guide nonprofit organizations that are planning or running mobile market programs. If successful, the next step for this program would be to test its implementation in cooperation with multiple nonprofit organizations in different communities and populations.

This research design addressed several practical concerns that are unique to the evaluation of food retail interventions. The study methods balanced the need to maintain engagement with community partners who were hosting the VV program and assisting with recruitment and the need for research integrity. The original study plan was to randomize sites as one large group, however, it became clear throughout the site recruitment process that this would result in significant delays for the research. A detailed discussion of the recruitment process can be found elsewhere, ${ }^{32}$ but ultimately it was decided that sites should be randomized based on similar timelines after they had completed the majority of data collection. This helped to ensure similarity between intervention and control sites with regard to seasonality and limit the lag time between baseline and the start of the VV program, as sites needed at least 2 months from the point of randomization to launch a VV program. Although the intervention group was larger, this may have occurred because the participant pool (ie, the number of people who completed interest forms) was larger at intervention sites due to the fact that those sites were larger and/or their interest form collection periods were longer. ${ }^{26,32}$ While recruitment rates were slightly higher for the interventions sites $(40.8 \%)$ vs control sites (36.8\%), ${ }^{26}$ these difference were not statistically significant $(P=0.36)$.

Despite adaptations made to the recruitment process, recruitment goals were still not reached. Limited funding and grant timelines (this was initially funded as a 2-year evaluation but ultimately took almost 4 years) hindered expansion of data collection to more $\operatorname{sites}^{32}$ and reduced the power of the study. A detailed discussion of the implications of the sample size can be found in the main outcomes paper. ${ }^{26}$ Future research should consider employing strategies suggested in the recruitment paper for this study, such as improved community engagement, ${ }^{32}$ or consider natural experiments or other designs, such as a time series, that do not require randomization. ${ }^{54}$

One major challenge of conducting an efficacy trial of an intervention that requires paid opt-in (ie, participants need to choose to buy a product if they want to benefit from the intervention) is that many people may decide not to purchase the product and thus never receive any intervention dosage. The interest form process, newsletters, and vouchers were used as strategies to provide enough intervention exposure to be able to determine program efficacy. Interest forms were used to ensure that VV had enough participants to be sustainable and that individuals recruited for the study would be likely to use the VV program. While the use of interest forms for recruitment limits generalizability of the results to individuals with an interest in buying more $\mathrm{F} / \mathrm{V}$, it was also important for an efficacy trial to have as many research participants that use VV as possible. Providing newsletters and a voucher for a free share to every research participant ensured a minimal level of exposure to the educational aspect of the VV and encouraged participants to try VV at least once. While these were additions to the way the VV had been implemented previously by Community Nutrition 
Partnership (ie, at sites not part of this evaluation), they were feasible additions to the program that were planned with the VV team and could be easily implemented outside the context of this study. In addition to the vouchers and newsletters, the research team plans to conduct a sensitivity analysis to compare program users to nonusers. Usage data from the current trial can be used to inform future effectiveness trials and power analyses.

Baseline results indicate that the study reached a population that had a financial need for the program. Consistent with previous research among lower-income populations, participants reported few F/V-related barriers besides cost and time. ${ }^{15,55}$ Overall reported self-efficacy was generally good for purchasing, preparing, and eating $F / V$, but participants reported the lowest relative self-efficacy levels for buying more $\mathrm{F} / \mathrm{V}$ and trying new vegetables. On average, study participants believed that eating more F/V was of high importance, but despite this they consumed only a little more than 3 cups/day. This is lower than what is recommended by federal dietary guidelines, ${ }^{56}$ but consistent with other research among recipients of government assistance, who also may face financial barriers to purchasing F/V. ${ }^{57}$ It should be noted that this study used a modified version of the National Cancer Institute F/V screener and results may not be comparable with other studies. While changes were made as a result of usability testing with the target population, the validity of the modified screener is unknown.

While perceived access measures vary from study to study, the initial testing of the NEMS-P tool (from which our measures were drawn) indicated mean item scores ranging from 3.6 in lower-income communities to 4.5 in higher-income communities. $^{38}$ The lower-income neighborhood scores are comparable with our perceived access score for the home food environment, which averaged 3.5 per item (10.6 overall). This score generally indicates that participants felt they had some access to healthy foods. This subjective finding was confirmed by GIS data, indicating that, on average, participants had one supermarket or grocery store within a mile of their home.

\section{CONCLUSIONS}

These findings support the need for a program like VV, as the target population is currently not meeting daily recommendations for $\mathrm{F} / \mathrm{V}$ intake. The intervention components are designed to address the most frequently reported barriers to F/V consumption in this population. Specifically, VV aims to address financial barriers by offering low-cost produce, address time barriers by making $\mathrm{F} / \mathrm{V}$ available in convenient locations, and address self-efficacy for trying new vegetables by providing nutrition education, taste testing, and seasonal recipes.

\section{References}

1. Centers for Disease Control and Prevention. State-specific trends in fruit and vegetable consumption among adults-United States, 20002009. MMWR Morb Mortal Wkly Rep. 2010;59(35):1125-1130.

2. Centers for Diease Control and Prevention. The Power of Prevention: Chronic Disease...The Public Health Challenge of the 21st Century. Washington, DC: National Center for Chronic Disease Prevention and Health Promotion; 2009.

3. Centers for Disease Control and Prevention. State Indicator Report on Fruits and Vegetables, 2013. Atlanta, GA: Centers for Disease Control and Prevention, US Department of Health and Human Services; 2013.
4. Trust for America's Health. F as in Fat: 2011 Obesity Report. Washington, DC: Trust for America's Health; 2011.

5. Wang X, Ouyang Y, Liu J, et al. Fruit and vegetable consumption and mortality from all causes, cardiovascular disease, and cancer: Systematic review and dose-response meta-analysis of prospective cohort studies. BMJ. 2014;349:g4490.

6. Lopez RP. Neighborhood risk factors for obesity. Obesity (Silver Spring). 2007;15(8):2111-2119.

7. Centers for Disease Control and Prevention, US Department of Health and Human Services. State Indicator Report on Fruits and Vegetables 2009. https://www.cdc.gov/nutrition/downloads/StateIndicator Report2009.pdf. Accessed May 1, 2018.

8. Maddock J. The relationship between obesity and the prevalence of fast food restaurants: State-level analysis. Am J Heath Promot. 2004;19(2):137-143.

9. Morland K, Wing S, Roux AD. The contextual effect of the local food environment on residents' diets: The Atherosclerosis Risk in Communities Study. Am J Public Health. 2002;92(11):1761-1767.

10. Penchansky R, Thomas JW. The concept of access: Definition and relationship to consumer satisfaction. Med Care. 1981;19(2):127-140.

11. Algert SJ, Agrawal A, Lewis DS. Disparities in access to fresh produce in low-income neighborhoods in Los Angeles. Am J Prev Med. 2006;30(5):365-370.

12. Boyington JE, Schoster B, Remmes Martin K, Shreffler J, Callahan LF Perceptions of individual and community environmental influences on fruit and vegetable intake, North Carolina, 2004. Prev Chronic Dis. 2009;6(1):A04.

13. Reicks M, Randall JL, Haynes BJ. Factors affecting consumption of fruits and vegetables by low-income families. J Am Diet Assoc. 1994:94:1309-1311.

14. Yeh MC, Ickes SB, Lowenstein LM, et al. Understanding barriers and facilitators of fruit and vegetable consumption among a diverse multiethnic population in the USA. Health Promot Int. 2008;23(1):42-51.

15. Leone LA, Beth D, Ickes S, et al. Attitudes towards fruit and vegetable consumption and farmers' market usage among low-income North Carolinians. J Hunger Environ Nutr. 2012;7(1):64-76.

16. Caspi CE, Sorensen G, Subramanian SV, Kawachi I. The local food environment and diet: A systematic review. Health Place. 2012;18(5):1172-1187.

17. Brug J, Kremers SP, Lenthe F, Ball K, Crawford D. Environmental determinants of healthy eating: In need of theory and evidence. Proc Nutr Soc. 2008;67(3):307-316.

18. Sallis JF, Glanz K. Physical activity and food environments: Solutions to the obesity epidemic. Milbank Q. 2009;87(1):123-154.

19. Boone-Heinonen J, Gordon-Larsen P, Kiefe CI, Shikany JM, Lewis CE, Popkin BM. Fast food restaurants and food stores-Longitudinal associations with diet in young to middle-aged adults: The CARDIA study. Arch Intern Med. 2011;171(13):1162-1170.

20. Zenk N, Steven C, Rebecca L, Collins TD, et al. Diet and perceptions change with supermarket introduction in a food desert, but not because of supermarket use. Health Aff. 2015;34(11):1858-1868.

21. Abusabha R, Namjoshi D, Klein A. Increasing access and affordability of produce improves perceived consumption of vegetables in lowincome seniors. J Am Diet Assoc. 2011;111(10):1549-1555.

22. Freedman DA, Choi SK, Hurley T, Anadu E, Hebert JR. A farmers' market at a federally qualified health center improves fruit and vegetable intake among low-income diabetics. Prev Med. 2013;56(5):288-292.

23. Evans AE, Jennings R, Smiley AW, et al. Introduction of farm stands in low-income communities increases fruit and vegetable among community residents. Health Place. 2012;18(5):1137-1143.

24. Leone LA, Haynes-Maslow L, Ammerman AS. Veggie Van pilot study Impact of a mobile produce market for underserved communities on fruit and vegetable access and intake. J Hunger Environ Nutr. 2017;12(1):89-100.

25. Gans KM, Gorham G, Risica PM, et al. A multi-level intervention in subsidized housing sites to increase fruit and vegetable access and intake: Rationale, design and methods of the 'Live Well, Viva Bien' cluster randomized trial. BMC Public Health. 2016;16:521.

26. Leone LA, Tripicchio GL, Haynes-Maslow L, et al. Cluster randomized controlled trial of a mobile market intervention to increase fruit and vegetable intake among adults in lower-income communities in North Carolina. Int J Behav Nutr Phys Act. 2018;15:2. 
27. Haynes-Maslow L, Parsons SE, Wheeler SB, Leone LA. A qualitative study of perceived barriers to fruit and vegetable consumption among low-income populations, North Carolina, 2011. Prev Chronic Dis. 2013;10:E34.

28. Haynes-Maslow L, Auvergne L, Mark B, Ammerman A, Weiner BJ Low-income individuals' perceptions about fruit and vegetable access programs: A qualitative study. J Nutr Educ Behav. 2015;47(4): 317-324.e311.

29. Robinson T. Applying the socio-ecological model to improving fruit and vegetable intake among low-income African Americans. J Community Health. 2008;33(6):395-406.

30. McLeroy KR, Bibeau D, Steckler A, Glanz K. An ecological perspective on health promotion programs. Health Educ Q. 1988;15(4):351-377.

31. Bandura A. Human agency in social cognitive theory. Am Psychol. 1989;44(9):1175-1184.

32. Tripicchio GL, Grady Smith J, Armstrong-Brown J, et al. Recruiting community partners for Veggie Van: Strategies and lessons learned from a mobile market intervention in North Carolina, 2012-2015. Prev Chronic Dis. 2017;14:E36.

33. Qualtrics [computer program]. Provo, UT: Qualitrics; 2017.

34. Carbone ET, Campbell MK, Honess-Morreale L. Use of cognitive interview techniques in the development of nutrition surveys and interactive nutrition messages for low-income populations. J Am Diet Assoc. 2002;102(5):690-696.

35. Thompson FE, Byers T. Dietary assessment resource manual. J Nutr. 1994;124(11 suppl):2245s-2317s.

36. Thompson FE, Subar AF, Smith AF, et al. Fruit and vegetable assessment: Performance of 2 new short instruments and a food frequency questionnaire. J Am Diet Assoc. 2002;2002(12):1764-1772.

37. de Boer MR, Waterlander WE, Kuijper LD, Steenhuis IH, Twisk JW. Testing for baseline differences in randomized controlled trials: An unhealthy research behavior that is hard to eradicate. Int J Behav Nutr Phys Act. 2015;12:4.

38. Green SH, Glanz K. Development of the Perceived Nutrition Environment Measures Survey. Am J Prev Med. 2015;49(1):50-61.

39. Ness AR, Powles JW. Fruit and vegetables, and cardiovascular disease: A review. Int J Epidemiol. 1997;26(1):1-13.

40. Dibsdall LA, Lambert N, Bobbin RF, Frewer LJ. Low-income consumers' attitudes and behaviour towards access, availability and motivation to eat fruit and vegetables. Public Health Nutr. 2003;6(2):159-168.

41. Anderson ES, Winett RA, Wojcik JR. Social-cognitive determinants of nutrition behavior among supermarket food shoppers: A structural equation analysis. Health Psychol. 2000;19(5):479-486.

42. BatchGeo [computer program]. Mountain View, CA: Google Inc; 2017.
43. Wright N, Ivers N, Eldridge S, Taljaard M, Bremner S. A review of the use of covariates in cluster randomized trials uncovers marked discrepancies between guidance and practice. J Clin Epidemiol. 2015;68(6):603-609.

44. Fleischhacker SE, Evenson KR, Sharkey J, Pitts SBJ, Rodriguez DA. Validity of secondary retail food outlet data: A systematic review. Am J Prev Med. 2012;45(4):462-473.

45. Jilcott SB, McGuirt JT, Imai S, Evenson KR. Measuring the retail food environment in rural and urban North Carolina counties. J Public Health Manag Pract. 2010;16(5):432-440.

46. Fleischhacker SE, Rodriguez DA, Evenson KR, et al. Evidence for validity of five secondary data sources for enumerating retail food outlets in seven American Indian communities in North Carolina. Int J Behav Nutr Phys Acty. 2012;9:137.

47. US Census Bureau. North American Industry Classification System. Washington, DC: US Census Bureau; 2012.

48. ArcGIS [computer program]. Version 10.2. Redlands, CA: Environmental Systems Research Institute; 2013.

49. Donner A, Klar N. Statistical considerations in the design and analysis of community intervention trials. J Clin Epidemiol. 1996;49(4):435-439.

50. Donner A, Klar N. Design and Analysis of Cluster Randomization Trials in Health Research. New York, NY: Oxford University Press; 2000.

51. Leone LA, Allicock M, Pignone MP, et al. Cluster randomized trial of a church-based peer counselor and tailored newsletter intervention to promote colorectal cancer screening and physical activity among older African Americans. Health Educ Behav. 2016;43(5):568-576.

52. STATA [computer program]. Version 9. College Station, TX: StataCorp; 2005.

53. Bleich SN, Segal J, Wu Y, Wilson R, Wang Y. Systematic review of community-based childhood obesity prevention studies. Pediatrics. 2013;132(1):e201-e210.

54. Taillie LS, Grummon AH, Fleischhacker S, Grigsby-Toussaint DS, Leone L, Caspi CE. Best practices for using natural experiments to evaluate retail food and beverage policies and interventions. Nutr Rev. 2017;75(12):971-989.

55. Cohen NL, Stoddard AM, Sarouhkhanians S, Sorensen G. Barriers toward fruit and vegetable consumption in a multiethnic worksite population. J Nutr Educ. 1998;30:381-386.

56. National Center for Health Statistics. Health, United States, 2004 With Chartbook on Trends in the Health of Americans. Hyattsville, MD: National Center for Health Statistics; September 2004. Report No. 2004-1232.

57. Olsho LE, Klerman JA, Wilde PE, Bartlett S. Financial incentives increase fruit and vegetable intake among Supplemental Nutrition Assistance Program participants: A randomized controlled trial of the USDA Healthy Incentives Pilot. Am J Clin Nutr. 2016;104:423-435. 


\section{AUTHOR INFORMATION}

L. A. Leone is an assistant professor of community health and health behavior, School of Public Health and Health Professions, University at Buffalo, Buffalo, NY; at the time of the study, she was a research assistant professor of nutrition, Gillings School of Global Public Health, and a research fellow, Center for Health Promotion and Disease Prevention, University of North Carolina at Chapel Hill. G. L. Tripicchio is an assistant professor, Department of Social and Behavioral Sciences and the Center for Obesity Research and Education, College of Public Health, Temple University, Philadelphia, PA; at the time of the study, she was a doctoral student and graduate research assistant, Department of Nutrition, Center for Health Promotion and Disease Prevention, University of North Carolina at Chapel Hill. L. Haynes-Maslow is an assistant professor and extension specialist, Department of Agricultural and Human Sciences, North Carolina State University, Raleigh; at the time of the study, she was a doctoral candidate and health care quality and patient outcomes predoctoral fellow, Department of Health Policy and Management, University of North Carolina, Gillings School of Global Public Health, Chapel Hill. J. McGuirt is an assistant professor, Department of Nutrition, University of North Carolina at Greensboro; at the time of the study, he was a graduate research assistant/doctoral student, University of North Carolina at Chapel Hill. J. S. Grady Smith is a project coordinator, Z. Gizlice is director of the biostatistical support unit, and A. Ammerman is a professor of nutrition, Gillings School of Global Public Health, and director, Center for Health Promotion and Disease Prevention (a CDC Prevention Research Center), University of North Carolina at Chapel Hill. J. Armstrong-Brown is a research public health analyst, RTI International, Research Triangle Park, NC; at the time of the study, she was a postdoctoral fellow, Carolina Program in Health and Aging Research, University of North Carolina at Chapel Hill. S. D. Kowitt is a postdoctoral fellow, University of North Carolina at Chapel Hill; at the time of the study, she was a doctoral student, Department of Health Behavior, University of North Carolina at Chapel Hill.

Address correspondence to: Lucia A. Leone, PhD, Community Health and Health Behavior, School of Public Health and Health Professions, University at Buffalo, 333 Kimball Tower, 3435 Main St, Buffalo, NY 14214-8028. E-mail: lucialeo@buffalo.edu

\section{STATEMENT OF POTENTIAL CONFLICT OF INTEREST}

L. A. Leone, L. Haynes-Maslow, and J. Armstrong-Brown are unpaid board members for Community Nutrition Partnership, the nonprofit organization that runs the Veggie Van program. No potential conflict of interest was reported by the other authors.

\section{FUNDING/SUPPORT}

This study was funded by the National Cancer Institute (1R21CA173042). In addition, some of L. A. Leone's effort was supported by the Cancer Health Disparities Training Program (1T32CA128582) and the 3E program on Built Environment, Health Behavior, and Health Outcomes at the University at Buffalo. L. Haynes-Maslow's effort was supported by Health Care Quality and Patient Outcomes Pre-doctoral Fellowship (2T32NR008856). The Veggie Van program was funded by a grant from the Blue Cross and Blue Shield Foundation of North Carolina and the US Department of Agriculture's Local Food Promotion Program.

\section{ACKNOWLEDGEMENTS}

The authors would like to thank Veggie Van's staff, customers, and host sites for their work on this project.

\section{AUTHOR CONTRIBUTIONS}

L. A. Leone, Z. Gizlice, A. Ammerman, and L. Haynes-Maslow contributed to study design and oversight. G. L. Tripicchio, J. McGuirt, J. S. Grady Smith, J. Armstrong-Brown, and S. D. Kowitt assisted with study recruitment and data collection. G. L. Tripicchio, Z. Gizlice, and L. A. Leone analyzed the data. L. A. Leone and G. L. Tripicchio drafted the manuscript. All authors provided edits and additions to the manuscript and approved the final version. 